EDITORIAL

DOl: https://doi.org/10.47796/ing.v2i2.407

\title{
La investigación pospandemia
}

La organización Mundial de la Salud (OMS) se vio envuelta en múltiples controversias a raíz del manejo de la pandemia, tal como afirma Cortez (2020) quedó en medio de un no declarado enfrentamiento entre actores del sistema internacional, este problema es ocasionado principalmente por el desconocimiento del virus SARS CoV-2 al ser un organismo que tiene efectos sin precedentes en la humanidad que hasta el día de hoy existen poblaciones en confinamiento y que a corto plazo no está asegura la dotación de las vacunas para poblaciones como la nuestra. Por ello la pregunta es ¿Cuánto más durará la pandemia?, la respuesta es que nadie sabe a ciencia cierta, en consecuencia se suponen cambios radicales cuando se vuelva a la nueva normalidad,

No obstante la academia ha normalizado sus quehaceres de manera virtual, medio poco común aunque creciente antes de la pandemia, a corto plazo seguirá siendo la modalidad más utilizada, por ello otra cuestión es; ¿será el futuro también de las acciones relacionadas con las actividades de investigación?, la respuesta está en la capacidad de adaptación de los investigadores y principalmente de las características de las pesquisas. De cualquier forma, lo rescatable de la pandemia es el derribo de las barreras digitales y el impulso de la actuación de la ciencia en medios digitales, la inteligencia artificial, realidad aumentada y realidad virtual, por ello la tarea de los investigadores es plantear soluciones a partir de la experiencia y sin duda cualquier disciplina tiene que ver en mayor o menor grado con el problema actual y su solución, aplicando los más rigurosos estándares para que no quepan dudas y atendiendo los principios de justicia, equidad y solidaridad, lo último es importante porque hay una pseudociencia basada en prácticas, experiencias y creencias que no utilizan el método científico y aprovechan la necesidad de resultados inmediatos reproduciendo falacias y recomendaciones inútiles en tiempos difíciles como el que estamos viviendo y ponen en riesgo - aunque minúsculo- de pervertir el conocimiento científico, entonces una tarea importante en la pospandemia es trascender el conocimiento científico, perpetuarlo, perfeccionarlo e influir fuertemente a la sociedad.

Otro punto importante en la pospandemia es priorizar investigaciones multidisciplinarias y transdisciplinarios que empleen recursos compartidos para encontrar soluciones conjuntas, para ese propósito es importante que los instrumentos y metodologías sean repensados para virtualidad a fin de llegar a la población de estudio de manera distinta y así entender las consecuencias del problema y dar soluciones. 
Por lo tanto, los retos de la investigación pospandemia es proponer soluciones que aminoren los efectos del Covid 19 y que den respuestas a la nueva forma de vida llamada "nueva normalidad" en todas las áreas de desarrollo humano con énfasis en la justicia, equidad y solidaridad y, por otro lado continuar con las investigaciones en un entorno colaborativo adaptado a la virtualidad y sobre todo valorizar los aportes actuales que están dando respuestas claras que trascienden y alcanzan objetivos que beneficia a la sociedad, este es un propósito magnánimo de la revista "Ingeniería Investiga" como espacio académico y científico que se alinea a ciencia abierta.

Dr. Arcadio Atencio Vargas

Director revista Ingeniería Investiga Decano Facultad Ingeniería - UPT

\section{Bibliografía}

Carvalho, Marilia Sá, Lima, Luciana Dias de, y Coeli, Cláudia Medina. (2020). Ciencia en tiempos de pandemia. Cadernos de Saúde Pública, 36(4), e00055520. Epub April 06, 2020. https://doi.org/10.1590/0102-311×00055520

CLACSO, Consejo Latinoamericano de Ciencias Sociales (2020). Observatorio Social del Coronavirus. Pensar la pandemia. https://n9.cl/p394y

Cortez J., (2020). El sistema internacional post pandemia... ¿Cuál sistema? Disponible en https://n9.cl/85lz

Dwanny Rodriguez (2020). La investigación y las estrategias de investigadores en tiempos de pandemia | Fundación Universitaria Los Libertadores, disponible en https://n9.cl/yvcs

El impacto del Covid-19 en la investigación de tesis y la post pandemia (2020) - Publica o Perece. Disponible en https://n9.cl/7a90k

Lifshitz A. La pseudociencia y los falsos investigadores (2017). Med Int Méx. Jul; 33(4):439-441. 